\title{
Grêmio de Regatas Almirante Tamandaré: uma ameaça ao império identitário teuto- brasileiro no cenário do remo Porto-Alegrense
}

\author{
Carolina Fernandes da Silva* \\ Ester Liberato Pereira ${ }^{* *}$ \\ Janice Zarpellon Mazo****
}

\begin{abstract}
Resumo: A fundação do Grêmio de Regatas Almirante Tamandaré ameaçou a hegemonia de associações de remo com identidades culturais teuto-brasileiras em Porto Alegre. Esta associação foi fundada por luso-brasileiros, que buscaram construir novas representações identitárias em torno desta prática esportiva, modificando o cenário do remo na cidade. O Grêmio de Regatas Almirante Tamandaré iniciou uma nova fase para a prática esportiva em Porto Alegre. Além de mais espaço na imprensa, consolidou, no cenário esportivo porto-alegrense, uma associação que se aproximasse de uma identidade cultural brasileira. Ação que oportunizou disputas identitárias no cenário do associativismo do remo.
\end{abstract}

Palavras-chave: Remo. História do Esporte. Clubes.

\section{Considerações INICIAIS}

No cenário das associações de remo porto-alegrenses, imperavam representações de identidades culturais teuto-brasileiras até o princípio do século XX. Este panorama começou a ser alterado com a fundação das associações de remo pela iniciativa de imigrantes

\footnotetext{
'Doutoranda, Programa de Pós-Graduação em Ciências do Movimento Humano, Escola de Educação Física, Universidade Federal do Rio Grande do Sul, Porto Alegre, RS, Brasil. E-mail: carol_ed.fis@hotmail.com

"Doutoranda Programa de Pós-Graduação em Ciências do Movimento Humano, Escola de Educação Física, Universidade Federal do Rio Grande do Sul, Porto Alegre, RS, Brasil. E-mail: ester_lp@yahoo.com.br

"'Professora, Escola de Educação Física, Universidade Federal do Rio Grande do Sul, Porto Alegre, RS, BRASIL, E-mail: janmazo@terra.com.br
} 
portugueses e seus descendentes, os luso-brasileiros. O Grêmio de Regatas Almirante Tamandaré, fundado em 18 de janeiro de 1903, atuou de forma contundente na construção de representações identitárias ${ }^{1}$ brasileiras no remo.

Anteriormente à fundação do Grêmio de Regatas Almirante Tamandaré, os clubes de remo, em Porto Alegre eram hegemonicamente organizados por teuto-brasileiros, o que vinculava essa prática esportiva a este grupo específico. A instalação do Grêmio de Regatas Almirante Tamandaré foi uma reação às identidades teuto-brasileiras constituídas ao redor do remo, visando desenvolver um clube que fosse caracterizado como brasileiro, onde fosse possível falar apenas o idioma português (SILVA, 2011).

Até a fundação do Grêmio de Regatas Almirante Tamandaré, a frequência dos luso-brasileiros era mais evidenciada nos prados ${ }^{2}$ para assistir ao turfe. $\mathrm{O}$ prado era um local de sociabilidade, onde as famílias firmavam sua representação social na segunda metade do século XIX (HISTÓRIA..., 1997, p. 103). A elite luso-brasileira portoalegrense utilizava os prados como ambientes de agregação da comunidade (PEREIRA, 2008). O turfe, assim, atuou como uma fronteira simbólica de distinção dos luso-brasileiros em relação a outros grupos étnicos que tinham como espaço unificador as sociedades de ginástica e de tiro, como também de remo.

O turfe, que, em Porto Alegre, atingiu seu ápice no período de 1880 a 1894, aproximadamente, com o funcionamento de quatro

\footnotetext{
${ }^{1}$ Para Cuche (1999), a identidade cultural exprime o resultado das diversas interações entre o indivíduo e o seu ambiente social, próximo ou distante. Tal identidade cultural pode ser reconstruída, por exemplo, por meio de uma re-significação dos esportes como representações culturais de uma comunidade étnica. A re-significação de representações culturais é uma forma de reconstruir identidades, entendendo que na perspectiva de Certeau (2008) a re-significação de práticas e representações culturais constituem as práticas pelas quais usuários se apropriam do espaço organizado pelas técnicas da produção sociocultural. A identidade cultural pode ser entendida, assim, enquanto representação, uma construção imaginária de sentido. Desta maneira, produz coesão social e organiza um sistema compreensivo a partir da ideia de pertencimento (PESAVENTO, 2008).

Faz-se importante esclarecer que, ao consultarem-se dicionários da língua portuguesa, se pôde encontrar o emprego como sinônimos dos conceitos de "hipódromo" e "prado". De acordo com Bissón (2008), o termo "prado" teve sua origem em razão das amplas áreas verdes onde eram construídos os hipódromos no estado do Rio Grande do Sul. Em função disto, os frequentadores começaram a denominar estes locais de prados, já que todos eles se situavam em meio a campinas planas, cobertas de pastagens.
} 
prados na cidade (HISTÓRIA..., 1997), começou a enfraquecer de forma simultânea à transição para um novo modelo sociocultural. As significativas transformações socioeconômicas de Porto Alegre, destacadas por Franco (1998) e marcadas pelo aumento populacional, processos de urbanização e modernização, constituem o contexto propício à introdução de novas práticas esportivas, como também à organização de associações. Nessa conjuntura, os luso-brasileiros escolhem um esporte que, até momento, estava envolto por representações de identidades culturais teuto-brasileiras: o remo; a partir daí, desencadeia a organização de suas associações esportivas.

A distinção entre grupos se processa pela produção de identificação entre os indivíduos de mesma origem, ao mesmo tempo em que são estabelecidos limites sociais simbólicos deste grupo em relação aos outros (SILVA; PEREIRA; MAZO, 2012). Tal processo de "demarcação de fronteiras de identidades" (CUCHE, 1999) envolve o confronto de identidades culturais, por meio da produção de representações e de práticas culturais. Conforme Burke (2005), as representações culturais podem ser expressas de diferentes formas, inclusive pelas práticas esportivas.

A construção de identidades é um fenômeno dinâmico, assim como a memória, que é constantemente atribuída de novos significados. Renovar a lembrança, mesmo ao receber novos significados, atualiza a memória cultural. Segundo Pollak (1992), em todos os níveis, a memória é um fenômeno construído, além de que há uma ligação fenomenológica muita estreita entre a memória e o sentimento de identidade.

Acrescenta-se que, de acordo com Le Goff (2003), a memória possui a propriedade de conservar certas informações que falam do passado, ou seja, certo modo de apropriação do tempo. Assim, a memória é uma operação ideológica, enquanto que a história é uma forma intelectual do conhecimento, ou seja, uma operação cognitiva. Com base nestes pressupostos, consideramos que os clubes se constituíram em "lugares de memória" do esporte e dos grupos sociais vinculados às práticas corporais e esportivas. O espaço social dos clubes está relacionado aos sujeitos e tempos de uma memória social. 
No presente estudo, pretendemos fazer uma releitura dos vestígios que foram captados acerca da associação que produziu fortes representações identitárias de um grupo social, a qual confrontou os teuto-brasileiros no campo esportivo, em um determinado período histórico. Mas, qual a importância de registrar tais acontecimentos de um clube de remo? Acredita-se que esta é uma forma de manter a história do clube sempre presente. Ao mesmo tempo em que, reconstituir a memória e divulgar o conhecimento para além de um espaço circunscrito, faz com que as pessoas reconheçam e se identifiquem com o lugar onde vivem.

Desta forma, a pesquisa parte da seguinte questão norteadora: como o Grêmio de Regatas Almirante Tamandaré estabeleceu novas representações de identidades culturais no cenário do remo portoalegrense, desde sua fundação, em 1903, até o ano de 1923? Neste referido ano, esta associação comemorou 20 anos de fundação e as representações de identidade cultural brasileira são realçadas.

Este estudo de caráter histórico valeu-se de fontes impressas. Foram analisadas notas e reportagens dos jornais "A Federação" e o "O Independente", de grande circulação em Porto Alegre no período demarcado para o estudo. Também foram consultados o "Álbum Comemorativo ao $20^{\circ}$ aniversário do Grêmio de Regatas Almirante Tamandaré" publicado em 1923 e o álbum "Rio Grande do Sul Sportivo"3 $^{\prime \prime}$ de 1919. O resultado da análise das informações coletadas nas fontes é apresentado nos tópicos que seguem.

\section{UM CLUBE DE REMO IDENTIFICADO COM OS BRASILEIROS}

Com a fundação do Grêmio de Regatas Almirante Tamandaré, o cenário do remo, envolto por representações identitárias teutobrasileiras, se modifica e ganha novas representações de uma identidade cultural brasileira. Desde meados do século XIX, o remo contribuiu para a fixação e estabelecimento de grupos sociais em

\footnotetext{
${ }^{3}$ Nestes álbuns comemorativos constam descritas atas, registros das provas, depoimentos e a trajetória do Grêmio de Regatas Almirante Tamandaré, durante os primeiros anos de estabelecimento, assim como dados dos outros clubes de remo fundados no fim do século XIX e início do século XX.
} 
Porto Alegre. O primeiro clube foi fundado, na cidade, em 21 de novembro de 1888 (MAZO; GAYA, 2006), com o nome de RuderClub Porto Alegre. Este clube de remo, juntamente com um clube organizado na cidade de Pelotas, está entre os pioneiros neste esporte no Estado.

Afundação do Ruder-Club Porto Alegre foi a primeira iniciativa de institucionalização do remo no Estado. Seus fundadores eram teuto-brasileiros e o clube utilizou o idioma alemão para a comunicação interna, limitando o acesso de pessoas que não falavam o idioma. Tal exigência pode ser evidenciada no jornal Gazetinha, cujo proprietário e editor era o luso-brasileiro Otaviano Manuel de Oliveira, que noticiou, no dia 8 de setembro de 1895 , duras críticas à germanização do Ruder Club Porto Alegre, referido no texto como Club de Regatas Porto-Alegrense, em uma tradução para a língua portuguesa, já como forma de protesto (CLUB..., 1895, p. 1).

Nesta publicação, são expostas ideias de reação aos teutobrasileiros, pois julga que a nacionalização foi "um desafio atirado aos brazileiros, foi um verdadeiro accinte que está mesmo a pedir 'revanche' completa e severa e que produziu o effeito de uma bofetada" (CLUB..., 1895, p. 1). O texto do jornal segue afirmando que "é doloroso para nós brazileiros natos, apreciar, [...] a grosseria com que certos extrangeiros mal educados pagam a hospitalidade proveitosa que acham em nossa querida Pátria" (CLUB..., 1895, p. 1). O discurso do editor do jornal registra a sua ofensa como um insulto à nação e tenta reportar, nas demais pessoas que se reconhecem possuidoras de uma identidade cultural brasileira, este mesmo sentimento.

Na nota redigida por Otaviano, no jornal Gazetinha, é retratada a busca por uma identidade cultural brasileira. Ele caracteriza os brasileiros como bons anfitriões, que propiciam "accolhimento amigo encontrado aqui pelos imigrantes que vêm trabalhar" (CLUB..., 1895, p. 1), e os alemães como ingratos, que "em vez de agradecer a este povo [brasileiro] os favores que no seio d'elle recebem, atiram-lhe 
offensas" (CLUB..., 1895, p. 1), além de condenar os brasileiros que apoiaram a nacionalização do clube. Provavelmente, este discurso foi impulsionado pela hegemonia do espaço teuto-brasileiro no cenário esportivo porto-alegrense.

Em 29 de outubro de 1892, é fundado, em Porto Alegre, o segundo clube de remo com identidade teuto-brasileira: o RuderVerein Germania. Dois anos após, estes dois clubes uniram-se para a fundação do Comitê de Regatas, com a finalidade de impulsionarem o desenvolvimento do remo. Do mesmo modo que os clubes anteriormente citados, o Comitê também utilizava o idioma alemão nos seus estatutos, atas, premiações e comunicação interna.

A primeira regata organizada por esta entidade ofereceu o prêmio Herausforderungpreis (LICHT, 1986) - em língua portuguesa, o Prêmio do Desafio. O jornal A Federação (REGATAS, 1895, p. 3), de propriedade de um luso-brasileiro, noticiou a regata e fez um apelo aos luso-brasileiros: "que os nossos patricios saibam imitar os clubs referidos, fundando outros e elevando-os pelo estimulo e pela concorrencia." Percebe-se o incentivo à instauração de um clube comidentidade cultural luso-brasileira, levando para o esporte disputas identitárias, existentes em outros domínios.

O jornal A Federação (REGATAS, 1903a), motivado por manifestações anteriores, com três dias de antecedência, noticiou a fundação do Grêmio de Regatas Almirante Tamandaré. Porém, não apenas informou a hora e o lugar da primeira reunião de instauração, mas buscou uma divulgação positiva da associação que estava para nascer, ao lembrar que já havia mais de 160 sócios inscritos. Esta associação passou a existir, oficialmente, no dia 18 de janeiro de 1903. Para além do remo, esta associação abarcaria outras práticas, como a natação, o tiro ao alvo e a ginástica, conforme a notícia do jornal: "sabemos que, além do sport do remo, o novo club de regatas a fundar-se nesta capital dedicar-se-á também á natação, tiro ao alvo, gymnastica, etc" (REGATAS, 1903a, p. 2).

A notícia da fundação de uma associação de remo, idealizada por luso-brasileiros, foi muito bem recebida pelos jornais da época, 
como os periódicos: A Federação e O Independente ${ }^{4}$. Estes jornais compartilhavam da ideia de que deveria ser fundada uma nova associação de remo com outras representações identitárias. Estes dois jornais são editados por luso-brasileiros e, anteriormente à fundação do Grêmio de Regatas Almirante Tamandaré, demonstraram a vontade de que houvesse, em Porto Alegre, outra associação de remo identificada com os luso-brasileiros. Isto justifica o amplo espaço dedicado às notícias desta nova associação de remo, inclusive com o resultado da primeira reunião. Tanto que, a partir deste momento, as regatas receberam maior atenção destes órgãos de divulgação. Assim, as disputas identitárias trouxeram, para a prática esportiva, a conquista de espaço na imprensa local.

$\mathrm{Na}$ época, principio do século $\mathrm{XX}$, o remo era o esporte de destaque em Porto Alegre, embora já houvesse, na cidade, algumas associações esportivas que ofereciam a prática do turfe, tênis, ciclismo, futebol, além da tradicional sociedade de ginástica, atual SOGIPA. Os clubes de remo figuravam no cenário esportivo desde a segunda metade do século XIX e se multiplicaram até o final da primeira década do século XX (RIO GRANDE DO SUL SPORTIVO, 1919, PIMENTEL, 1945, DAUDT, 1952). Estas associações congregavam diferentes grupos: teuto-brasileiros, lusobrasileiros e ítalo-brasileiros.

No dia 19 de janeiro de 1903, os leitores dos jornais O Independente (PRIMEIRA..., 1903) e A Federação (REGATAS, 1903b), se depararam com os resultados da reunião de fundação da nova associação de remo nascida em Porto Alegre. A Federação destaca a escolha da denominação do clube ter sido sugerida por um dos sócio-fundadores, Miguel Macalão, em homenagem a "um grande vulto da marinha nacional" (REGATAS, 1903b, p. 2), o Almirante Tamandaré. Ambos os jornais indicaram que a presidência e a vice-presidência do clube seriam ocupadas pelos luso-brasileiros Gaspar Fróes e Ricardo Machado (NOVO..., 1903).

${ }^{4} \mathrm{O}$ editor deste último jornal era Otaviano M. de Oliveira, o mesmo editor da Gazetinha, fechada em 1900, ano de fundação do O Independente. 
No comando do grupo de fundadores luso-brasileiros, estava o idealizador da associação, Gaspar Fróes de Azevedo, que era capitão de corveta da Capitania dos Portos, isto é, função de primeiro posto de oficial superior nas forças navais. Fróes era conhecido, na cidade, como um nacionalista. $\mathrm{O}$ jornal $\mathrm{O}$ Independente o caracterizava como o "bravo e brioso official da marinha que tantos serviços prestou á Pátria" (GASPAR..., 1908, p. 1). O capitão de corveta presidiu a reunião em que foi definido o nome e a comissão organizadora da associação esportiva.

Esta associação instalou-se em um barracão na Rua General Portinho, quase esquina com a Rua Andradas, próxima à Praça General Osório. Este barracão foi cedido pela Capitania dos Portos, provavelmente pela influência de Fróes, o que demonstra seu empenho na instauração (RIO GRANDE DO SUL SPORTIVO, 1919). O Grêmio de Regatas Almirante Tamandaré se estabeleceu distante das outras duas associações de remo da cidade, longe do ambiente teuto-brasileiro em que estas estavam localizadas e onde ocorriam as regatas. A partir disso, é possível traçar as formas com que o Grêmio busca demarcar fronteiras identitárias: uma delas é a distância estabelecida, diferenciando a associação até mesmo na localização.

A Rua General Portinho fica na zona central de Porto Alegre (FRANCO, 1998). Neste local, onde se encontrava o barracão, se situa, até hoje, a Capitania dos Portos. Este órgão da Marinha Brasileira tem a responsabilidade da emissão local sobre a segurança da navegação. Deste modo, é um órgão de segurança nacional, o que identifica seu prédio como um representante do governo brasileiro em Porto Alegre. Assim, também carrega a representação do pertencimento da cidade à nação brasileira. Segundo Thiesse (2000, p. 229), pertencer à nação é ser um dos herdeiros de seu patrimônio comum e indivisível, conhecê-lo e venerá-lo.

O prédio da Capitania dos Portos fazia parte do patrimônio nacional como um monumento cultural, assim como cultuava representações oficiais: a Bandeira e o Hino Nacional. Além de seguir suas leis e as fazer cumprir, mantém elevada, em um mastro 
na fachada principal do prédio, um dos principais símbolos nacionais: a Bandeira do Brasil. $\mathrm{O}$ valor dos símbolos nacionais era bastante exaltado, como nos demonstra uma nota no jornal $\mathrm{O}$ Independente (COUSAS..., 1903, p. 1) que diz: "o Hynno Nacional e o Pavilhão Patrio, nelles se synthetizam a nossa veneração aos antepassados heroes, o nosso culto à liberdade, o nosso patriotismo". Mais uma vez, o sentimento de pertencimento a uma identidade cultural coletiva é expresso por meio do emprego repetitivo do pronome possessivo na primeira pessoa do plural (THIESSE, 2000).

Outra representação desta diferenciação foi a adoção da língua portuguesa, utilizada como uma distinção simbólica dos outros clubes que utilizavam o idioma alemão. Hobsbawn (1990, p. 33) nos esclarece que "a língua se tornou um exercício mais deliberado de engenharia social na medida em que seu significado simbólico passou a prevalecer sobre seu uso real", de forma que os frequentadores dos clubes de remo utilizavam os idiomas originários do seu país de procedência, principalmente, para afirmar sua identidade cultural, manter sua memória cultural, se reconhecerem entre si e se diferenciarem de outros imigrantes e seus descendentes. Direcionando-se para a construção de uma identidade cultural brasileira e reforçando o entendimento de que a cidadania e a nacionalidade são definidas pelo país de nascimento, "os luso-brasileiros consideravam-se cidadãos brasileiros de nacionalidade brasileira" (MAZO; FROSI, 2008, p. 58). Este pensamento que vai de encontro à concepção teuto-brasileira, que estabelecia a cidadania pela participação política e econômica no país, e que a nacionalidade estava relacionada à filiação cultural.

A escolha do nome da associação também foi elaborada visando uma identidade cultural brasileira, pois o Almirante Tamandaré, além de ser um herói da marinha brasileira, nasceu na vila de São José do Norte, no Estado do Rio Grande do Sul. Consta, na primeira ata oficial de fundação, que a escolha pelo nome do almirante seria "em homenagem aos feitos gloriosos daquele ínclito rio-grandense" (CASTELLO, 1923, p. 5). Desta forma, o objetivo não era apenas afirmar a identidade cultural brasileira, mas também relembrar que 
este almirante brasileiro, símbolo de heroísmo, era sul-rio-grandense, assim como o clube. Desenvolver esta ligação com o Almirante Tamandaré foi uma estratégia de representar que, de maneira semelhante à trajetória de vida de seu patrono, esta associação de remo sul-rio-grandense se destacaria no cenário nacional, por suas conquistas.

Além do nome do Almirante Tamandaré no título da associação, os fundadores utilizaram a palavra "grêmio". O termo possui o mesmo significado, na língua portuguesa, que club, na língua inglesa e, aproxima-se do significado do termo verein, em alemão. A utilização do termo no idioma nacional serviu para potencializar a sua diferenciação das associações dos teuto-brasileiros. Um dos elementos essenciais da nação é o seu idioma, segundo Thiesse (2000); a nação existe porque possui uma língua.

Esta associação, a exemplo das anteriores, também não instaurou, nos seus estatutos, a exigência de que os associados deveriam ter nacionalidade específica - no caso, a brasileira -, mas, sim, que os estrangeiros entendessem a língua portuguesa. Tanto que, no livro comemorativo Rio Grande do Sul Sportivo (1919) ${ }^{5}$, há uma manifestação a favor de exigir o conhecimento da língua portuguesa aos estrangeiros. Esta era uma estratégia para a manutenção de uma identidade cultural brasileira. Para os organizadores da obra, isso impõe "o respeito devido a nossa terra e ao nosso pavilhão, respeito a que temos direito como povo emancipado que o somos" (RIO GRANDE DO SUL SPORTIVO, 1919, p. 162). Nesta afirmação, é revelada a identidade cultural dos organizadores, pois estes se definem brasileiros ao utilizar o sujeito subentendido "nós", além de exprimir o seu sentimento nacionalista. Em conformidade com Thiesse (2000), falar a língua da nação, para os cidadãos, era entendido como um dever; todos os seus membros devem compreendê-la e utilizá-la.

Outra representação da identidade cultural brasileira utilizada foram palavras no idioma dos primeiros habitantes brasileiros: as

${ }^{5}$ Trata das diversas associações de remo, porém determina maior espaço para duas associações com nomes de heróis brasileiros. 
tribos indígenas que povoavam o país. Os fundadores do clube resignificaram esta característica em todos os seus barcos. Possivelmente, os idealizadores tinham apenas a intenção de lembrar os povos indígenas como símbolos brasileiros, mas não se preocuparam com a fidedignidade das palavras serem em dialeto tupi-guarani ${ }^{6}$. São designadas como tupi-guarani as tribos indígenas que habitavam o litoral brasileiro, quando houve a chegada dos portugueses ao Brasil em 1500. Ainda, como refere Boudin (1963, p. 22): "Os tupis-guaranis formam uma mesma nação, usando de preferência o guarani para as tribos do sul - além de Paraguay, Argentina, Uruguay -, e tupi para os elementos de centro e norte do país". O renovar da lembrança de que os ancestrais fundadores do país foram povos indígenas, faz parte do movimento de construção de uma identidade cultural brasileira, que se iniciava no período.

Os elementos básicos, citados por Thiesse (2000), para que se construa uma identidade para a nação são, em sua maioria, buscados em uma memória cultural, como: os ancestrais fundadores, a história, os heróis, o folclore, a língua, os monumentos e certas paisagens. Desta forma, encontramos, nas representações de identidade cultural brasileira, construídas pelos fundadores do Grêmio de Regatas Almirante Tamandaré, elementos da memória cultural brasileira, como os ancestrais fundadores que, em seu idioma, estão representados nos barcos.

$\mathrm{Na}$ regata inaugural do clube, os barcos participantes foram o Tocantins, o Tramandahy e o Teffé (REGATAS, 1903c). Todos os barcos foram batizados com nomes indígenas que começam com a letra "T", porque, por meio da repetição, faz-se uma construção simbólica no imaginário coletivo. Como o próprio nome da associação - Tamandaré - começa com T, esta se tornou uma reprodução simbólica que os luso-brasileiros ressignificaram como uma forma de estruturar, na memória coletiva, um elo com a instituição. Até 1919, o Grêmio de Regatas Almirante Tamandaré possuía uma grande frota. No quadro abaixo, estão relacionados os barcos, seu

${ }^{6}$ Idioma indígena.

Movimento, Porto Alegre, v. 20, n. 01, p. 59-79, jan/mar de 2014. 
tipo, o construtor e o país que este foi confeccionado (RIO GRANDE DO SUL SPORTIVO, 1919, CASTELLO, 1923).

Quadro 1 - Frota do Grêmio de Regatas Almirante Tamandaré, até 1919.

\begin{tabular}{|c|c|c|c|c|}
\hline Nome & Modelo & Construtor & Origem & Madrinha \\
\hline Tory & skiff & F. Leux & $\begin{array}{c}\text { Informação não } \\
\text { localizada }\end{array}$ & Gilda Totta \\
\hline Tieté & $\begin{array}{l}\text { Gig, a dois } \\
\text { remos }\end{array}$ & Max Yanke & $\begin{array}{c}\text { Rio de Janeiro - } \\
\text { Brasil }\end{array}$ & Lola Weyrauch \\
\hline Tamoyo & $\begin{array}{l}\text { Gig, a quatro } \\
\text { remos }\end{array}$ & Telliers Fils & Paris & $\begin{array}{l}\text { Ophelia Pinto } \\
\text { Bento }\end{array}$ \\
\hline Tapajoz & $\begin{array}{l}\text { Gig, a quatro } \\
\text { remos }\end{array}$ & F. Leux & $\begin{array}{c}\text { Informação não } \\
\text { localizada }\end{array}$ & Julianna Ribeiro \\
\hline Toropy & $\begin{array}{l}\text { Gig, a quatro } \\
\text { remos }\end{array}$ & Max Yanke & $\begin{array}{c}\text { Rio de Janeiro - } \\
\text { Brasil }\end{array}$ & Gentila Santos \\
\hline Tabajara & $\begin{array}{l}\text { Gig, a quatro } \\
\text { remos }\end{array}$ & Telliers Fils & Paris & $\begin{array}{c}\text { Célia Viana } \\
\text { Ahrends }\end{array}$ \\
\hline Tyapyra & $\begin{array}{l}\text { Yole, a quatro } \\
\text { remos }\end{array}$ & Max Yanke & $\begin{array}{c}\text { Rio de Janeiro - } \\
\text { Brasil }\end{array}$ & Olga Marcher \\
\hline Toryba & $\begin{array}{l}\text { Gig, a quatro } \\
\text { remos }\end{array}$ & Max Yanke & $\begin{array}{c}\text { Rio de Janeiro - } \\
\text { Brasil }\end{array}$ & $\begin{array}{c}\text { Luiza de Azevedo } \\
\text { Bastian }\end{array}$ \\
\hline Tibagy & $\begin{array}{l}\text { Gig, a quatro } \\
\text { remos }\end{array}$ & $\begin{array}{l}\text { Carlos } \\
\text { Remedi }\end{array}$ & $\begin{array}{l}\text { São Paulo - } \\
\text { Brasil }\end{array}$ & Edith Jacobus \\
\hline Tариуа & $\begin{array}{l}\text { Gig, a seis } \\
\text { remos }\end{array}$ & Max Yanke & $\begin{array}{c}\text { Rio de Janeiro - } \\
\text { Brasil }\end{array}$ & $\begin{array}{c}\text { Emira Ferreira de } \\
\text { Almeida }\end{array}$ \\
\hline Tijuca & $\begin{array}{l}\text { Gig, a seis } \\
\text { remos }\end{array}$ & F. Leux & $\begin{array}{c}\text { Informação não } \\
\text { localizada }\end{array}$ & $\begin{array}{c}\text { Helenita } \\
\text { Mostardeiro }\end{array}$ \\
\hline Tupynambá & $\begin{array}{l}\text { Out-rigger, a } \\
\text { oito remos }\end{array}$ & Telliers Fils & Paris & Esther Gomes \\
\hline
\end{tabular}

Fonte: Quadro organizado pelos autores, a partir de informações encontradas nos álbuns Rio Grande do Sul Sportivo, (1919) e Álbum commemorativo ao $20^{\circ}$ aniversário do Gremio de Regatas Almirante Tamandaré 1903-1923 (CASTELLO, 1923). 
Castello (1923, p. 39) alude à correlação feita pelo clube com o nome tupi em um de seus barcos: "os tabajaras, que faziam parte da tribu tupy, habitavam o litoral de Pernambuco no Rio de Grande do Norte, tendo elles auxiliado fortemente os portugueses nas lutas contra os cahetés". Partindo da afirmação de Ortiz $(1994$, p. 8) que "toda a identidade é uma construção simbólica", percebe-se que se inventou uma tradição, ao utilizar os nomes em tupi-guarani que se iniciam pela letra "T", em todos os barcos que faziam parte da frota do Grêmio de Regatas Almirante Tamandaré.

Oliven (1992, p. 20) afirma que "a memória coletiva está ligada a um grupo relativamente restrito e portador de uma tradição, aproximando-se do mito e manifestando-se através da ritualização dessa tradição". A criação da identidade do Grêmio de Regatas Almirante Tamandaré tinha por objetivo desenvolver uma associação onde os elementos constitutivos de representação brasileira, no esporte do remo, tivessem um ambiente onde pudessem cultivar uma identidade cultural brasileira.

Os barcos foram confeccionados em diferentes localidades. Provavelmente, nestas cidades e países, o remo era um esporte bastante desenvolvido, pois havia demanda dos produtos específicos para a prática e mercado para construtores especializados. Vê-se que, no Brasil, o Rio de Janeiro e São Paulo já eram referência no esporte. Nestes Estados, o remo já era praticado desde a década de 1870. Em vista da expansão do mercado, surgiu a necessidade de haver fabricantes de barcos próprios para a prática. O Maranhão também integra os Estados brasileiros nos quais houve a tentativa de inserir o remo, no início do século XX. Entretanto, seu desenvolvimento foi inverso ao dos Estados citados anteriormente.

No Maranhão, em um período contemporâneo ao da fundação do Grêmio de Regatas Almirante Tamandaré houve a intenção de inserir o remo utilizando os rios Anil e Bacanga. Para tanto, foi criado o Clube de Regatas Maranhense; contudo, a ideia não se consolidou, pois faltaram recursos para a aquisição das embarcações apropriadas, assim como o apoio do comércio e das autoridades estabelecidas. Em 13 de setembro de 1908, houve uma nova tentativa. Voltou-se a 
falar na implantação do remo, no Estado, chegando a ser organizada uma competição; porém, a re-implantação do clube só se realizou em 1909 (VAZ, 2005). Percebe-se que a organização desta prática em clubes foi tardia em relação aos Estados do Rio de Janeiro, São Paulo e Rio Grande do Sul. Faz-se a ressalva que os clubes de remo do Rio Grande do Sul se diferenciaram dos demais, pois havia pessoas que dominavam a técnica para a fabricação de barcos para a prática do esporte.

As madrinhas dos barcos tamandaristas possuíam, em maior parte, sobrenomes luso-brasileiros ou um sobrenome luso-brasileiro e um teuto-brasileiro. Por isso, supostamente, eram nascidas em solos brasileiros. Contudo, havia madrinhas com alcunhas de origem étnica definida como alemã, a exemplo, Lola Weyrauch e Olga Marcher. Ou seja, a associação aceitava, entre seus associados, elementos de outras etnias. Este indício também é visto nos nomes dos integrantes das guarnições que competiam na época.

\section{O GRÊmIo TaMANDARÉ COMPLETA 20 ANOS: REAFIRMAÇÃO dE UMA IDENTIDADE}

O Grêmio de Regatas Almirante Tamandaré era um espaço destinado as práticas esportivas majoritariamente para os lusobrasileiros Nos anos de 1920, quando a associação completava duas décadas de existência, fortalecia-se o movimento de construção da identidade cultural brasileira no país. Para tanto, foram buscadas representações que reavivassem uma memória cultural (ASSMANN, 1995), considerada como brasileira.

Nesta direção, a referida associação de remadores, também reportou representações da memória cultural brasileira. Quando completou 20 anos de fundação, em 1923, Castello organizou um livro comemorativo em sua homenagem, editado em um período pósPrimeira Guerra, quando o nacionalismo brasileiro era crescente. Neste período, adotar representações de uma identidade cultural brasileira era valorizado pelo contexto social. Castello (1923) fornece traços de realce quanto a algumas representações identitárias 
brasileiras adotadas pela associação. Apesar da ênfase dada pelo autor, este livro comemorativo permite a identificação das representações identitárias que os idealizadores do clube buscaram construir: "compreendiam o Sport como um meio para o desenvolvimento do organismo e para a formação completa da Nacionalidade. Assim, imaginavam no extremo sul da Pátria um systema de retemperar os liames da nacionalidade" (CASTELLO, 1923).

Segundo Melo (2006), o remo era caracterizado como o esporte do "exercício physico", usado para defender e propagar os benefícios dessa prática. O mesmo autor cita que este esporte era visto como da saúde, do desafio, que educa o músculo e a moral, "prática adequada a uma juventude altiva, forte e com 'liberdade de espírito' suficiente para conduzir a nação ao progresso necessário" (MELO, 2006, p. 8). Provavelmente, a escolha do esporte remo para instaurar a primeira associação com representações de uma identidade cultural brasileira, em Porto Alegre, foi por sua caracterização de esporte que fortalece os músculos e a moral (MELO, 2006), e inspirava o sentimento de nacionalidade.

Tais ideias foram expressas, na sede da associação, durante a reunião de instalação solene e inauguração do retrato do Almirante Tamandaré, que ocorreu no dia 7 de setembro de 1903, quando o orador oficial, Arthur Pinto da Rocha, discursou para um grande público que se fazia presente. Neste discurso, este se utilizou da narrativa do passado para reforçar, recorrentemente, os feitos e as glórias do patrono. Ao mesmo tempo em que construía o herói no imaginário coletivo, mirava um processo de transformação social, em direção ao nacionalismo da associação, com o objetivo de atrair um maior número de participantes. Para tanto, procurou a construção de uma memória coletiva, fazendo uma "constituição simbólica, que envolve várias batalhas simbólicas pela apropriação de eventos do passado que devem ser lembrados e a demarcação dos que devem ser esquecidos" (OLIVEIRA, 2003, p. 68).

Conforme Carvalho (1990), o herói tem de ter a cara da nação. Arthur Pinto da Rocha procura construir, em seu discurso, este 
simbolismo, ao se dirigir, seguidamente, aos jovens, e incutir-lhes a ideia de nacionalidade por meio do exemplo heroico da figura do Almirante Tamandaré na história do país. Para tanto, lista seus feitos em defesas nacionais entre 1823 e 1867, citando fatos ligados à memória brasileira, como a Independência do Brasil, a Batalha do Riachuelo e a Guerra do Paraguai: "em 1823 ligava o seu nome de bravo à história da nossa Independência, [...] e de 1865 a 1867 gravava seu nome heroico e forte nas escarpas do Paraguay" (CASTELLO, 1923, p. 11).

Desta forma, fez-se a construção do herói, um ser onipotente, que passa por um tempo de provações, no limite de suas forças, no qual é obrigado a travar um combate solitário com o mal até o triunfo final. De acordo com Araújo, citado por Oliveira (2003, p. 67), essa construção "implica o advento de um tempo de glorificação, baseado em torno de manifestações de orgulho e piedade, este é o perfil básico do herói que confirma sua excepcionalidade". Em outro momento de seu discurso, Rocha conclama a mocidade da época, presente na comemoração, a "moldar a sua pela alma do grande brasileiro" (CASTELLO, 1923, p. 11). Fazendo-os assumir um compromisso de honra com a nação, reforça uma associação destes jovens com uma identidade cultural brasileira, à qual o clube estava vinculado: "vós que preparareis para a direcção da pátria brasileira no seu brilhantíssimo futuro, que tendes o culto sagrado das glórias nacionaes, vós que escolhestes para symbolo dos vossos ideaes esse nome de guerra e de honra" (CASTELLO, 1923, p. 11).

Transformar o Almirante Tamandaré em herói, nos olhos dos associados do clube, é uma tática para "atingir a cabeça e o coração dos cidadãos" (CARVALHO, 1990, p. 55) e, assim, legitimar uma identificação. Segundo Carvalho (1990, p. 55), "os heróis são símbolos poderosos, encarnações de ideias e aspirações, pontos de referências, fulcros de identificação coletiva"; portanto, são instrumentos eficazes para serem reutilizados como representações de identidades culturais.

Nas disputas, o Grêmio de Regatas Almirante Tamandaré diferenciava-se por meio das cores de seu uniforme, azul marinho e o branco (REGATAS, 1911), com o emblema representado por uma 
âncora e dois remos cruzados. A âncora, no emblema do clube, representa a segurança durante a tempestade, o refúgio dos marinheiros, bem como liga a associação com os símbolos navais. Os remos atravessados afirmam a associação como dedicada a este esporte. Os trajes dos remadores, para a época, eram uma novidade, assim como as mudanças na estética corporal masculina (SILVA, 2011).

A fundação da nova associação, em conformidade com o livro comemorativo, Rio Grande do Sul Sportivo (1919, p. 161) foi destacada como uma "benéfica reação contra o elemento extrangeiro, que naquella época predominava no sport náutico local". Desta forma, o Grêmio de Regatas Almirante Tamandaré fixa uma identidade cultural brasileira no cenário do remo porto-alegrense; o modifica e estimula a competição entre associações, ao desenvolver fronteiras de identidades culturais.

\section{Considerações Finas}

O Grêmio de Regatas Almirante Tamandaré inseriu novas representações identitárias no cenário do remo em reação à hegemonia teuto-brasileira. Essa associação tornou-se um espaço de relações de lutas entre representações de identidades culturais, onde as regatas eram disputas para além da competição esportiva: as suas conquistas simbolizavam mudanças de posições hierárquicas entre identidades culturais, na busca por uma supremacia no remo. Esta associação procurava aproximar-se de uma identidade cultural brasileira; para tanto, adotou medidas como, por exemplo: a língua portuguesa tornou-se o idioma oficial; na sua denominação, ter como referência um almirante da Marinha Brasileira, nascido no Rio Grande do Sul; os barcos da flotilha eram batizados com nomes no idioma tupi-guarani e a sua instalação foi em um prédio que simbolizava a defesa dos mares nacionais e a organização do tráfego marítimo, em Porto Alegre. 
Regatta Bosom Almirante Tamandaré: a threat to the german-brazilian identity empire in Porto Alegre rowing scenery

Abstract: The foundation of Regatta Bosom Almirante Tamandare threatened the hegemony of rowing associations with German-Brazilian cultural identities, in Porto Alegre. This association was founded by LusoBrazilians, who sought to build new identity representations around this sport practice, changing the scene of rowing in the city. Regatta Bosom Almirante Tamandaré started a new phase for sports in Porto Alegre. Besides more space in the press, consolidated, in the sports scene in Porto Alegre, an association that approached a Brazilian cultural identity. This action favored identity disputes on the set of associations of rowing.

Keywords: Rowing. History of Sport. Clubs.

Gremio de Regata Almirante Tamandaré: una amenaza al imperio de identidad alemánbrasileña en el panorama del remo de Porto Alegre

Resumen: La fundación del Gremio de Regata Almirante Tamandaré amenazaba la hegemonía de las asociaciones de remo con identidades culturales alemán-brasileñas, en Porto Alegre. Esta asociación fue fundada por los luso-brasileños, que buscaban construir nuevas representaciones de identidad en torno a esta práctica deportiva, cambiando el panorama del remo en la ciudad. Este gremio comenzó una nueva etapa para el deporte en Porto Alegre. Además de más espacio en la prensa, ha consolidado una asociación que se acercó a una identidad cultural brasileña. Esta acción favoreció disputas de identidad en el conjunto de las asociaciones de remo.

Palabras-clave: Remo. Historia del deporte. Clubes. 


\section{REFERÊNCIAS}

ASSMANN, J. Collective Memory and Cultural Identity. New German Critique, n. 65, p. 125-133, 1995.

BISSÓN, C. Moinhos de Vento: histórias de um bairro de elite de Porto Alegre. Porto Alegre: Secretaria Municipal da Cultura, IEL, 2008.

BOUDIN, M. O simbolismo verbal primitivo: análise estruturalista de um dialeto tupi-guarani. Presidente Prudente: Faculdade de Filosofia, Ciências e Letras, 1963.

BURKE, P. O que é história cultural? Rio de Janeiro: Zahar, 2005.

CARVALHO, J. A Formação das Almas: o imaginário da República no Brasil. São Paulo: Companhia das Letras, 1990.

CASTELLO, J. Álbum commemorativo ao $20^{\circ}$ aniversário do Gremio de Regatas Almirante Tamandaré 1903-1923. Porto Alegre: Revista Vida Gaúcha, 1923.

CERTEAU, M. A invenção do cotidiano: 1. Artes de fazer. Petrópolis: Vozes, 2008.

CLUB de regatas, A Gazetinha, Porto Alegre, 08 set. 1895.

COUSAS pátrias. O Independente, Porto Alegre, 9 abr. 1903.

CUCHE, D. A noção de cultura nas ciências sociais. Bauru: EDUSC, 1999.

DAUDT, J. Brasileiros de cabelos loiros e olhos azuis. Porto Alegre: Catos, 1952.

GASPAR Pinto Fróes de Azevedo. O Independente, Porto Alegre, 5 nov. 1908.

FRANCO, S. C. Porto Alegre: guia histórico. 3. ed. rev. ampl. Porto Alegre: Ed. UFRGS, 1998.

HISTÓRIA ilustrada de Porto Alegre. Porto Alegre: CEEE, 1997.

HOBSBAWN, E. Nações e nacionalismo desde 1979: programa, mito e realidade.

Rio de Janeiro: Paz e Terra, 1990.

LE GOFF, J. História e memória. Campinas: Editora da Unicamp, 2003.

LICHT, H. O remo através dos tempos. Porto Alegre: CORAG, 1986.

MAZO, J.; GAYA, A. As associações desportivas em Porto Alegre, Brasil: espaço de representação da identidade cultural teuto-brasileira. Revista Portuguesa de Ciências do Desporto, Lisboa, v. 6, n. 2, 2006. 
MAZO, J.; FROSI, T. Em busca da identidade luso-brasileira no Associativismo esportivo em Porto alegre no princípio do século XX. Revista do Colégio Brasileiro de Ciências do Esporte, Campinas, v. 30, n. 2, p. 57-72, 2008.

MELO, V. Remo, modernidade e Pereira Passos: primórdios das políticas públicas de esporte no Brasil. Esporte e Sociedade, Rio de Janeiro, n. 3, jul./out. 2006.

NOVO club sportivo. O Independente, Porto Alegre, 18 jan. 1903.

OLIVEIRA, L. L. A construção do herói no imaginário do brasileiro de ontem e de hoje. In: PESAVENTO, Sandra (Org.). História cultural: experiências de pesquisa. Porto Alegre: Editora da UFRGS, 2003.

OLIVEN, R. A parte e o todo: a diversidade cultural no Brasil-Nação. Petrópolis: Vozes, 1992.

ORTIZ, R. Cultura brasileira e identidade nacional. 5. ed. São Paulo: Brasiliense, 1994.

PEREIRA, E. L. A prática do turfe em Porto Alegre (1875/1910): alguns tropeços em meio a um vitorioso galope. Monografia (Conclusão de Curso) - Escola de Educação Física, Universidade Federal do Rio Grande do Sul, Porto Alegre, 2008.

PESAVENTO, S. História e história cultural. 2. ed. Belo Horizonte: Autêntica, 2008.

PIMENTEL, F. Aspectos gerais de Porto Alegre. Porto Alegre: Imprensa Oficial, 1945.

POLLACK, M. Memória e identidade social. Revista Estudos Históricos, Rio de Janeiro, v. 5, n. 10, 1992.

PRIMEIRA reunião e installação. A Federação, Porto Alegre, 19 jan. 1903.

REGATAS. A Federação, Porto Alegre, 26 nov. 1895.

REGATAS. A Federação, Porto Alegre, 15 jan. 1903a.

REGATAS. A Federação, Porto Alegre, 19 jan. 1903b.

REGATAS. A Federação, Porto Alegre, 5 set. 1903c.

REGATAS. A Federação, Porto Alegre, 12 maio 1911.

RIO GRANDE DO SUL SPORTIVO. Álbum. Porto Alegre: Livraria do Globo, 1919.

SILVA, C. O remo e a história de Porto Alegre, Rio Grande do Sul: mosaico de identidades culturais no longo século XIX. Dissertação (Mestrado). - Escola de Educação Física, Universidade Federal do Rio Grande do Sul, Porto Alegre, 2011.

SILVA, C.; PEREIRA, E. L.; MAZO, J. Clubes sociais: práticas esportivas e identidades culturais. Licere, Belo Horizonte, v. 15, p. 1-21, 2012. 
THIESSE, A. A criação das identidades nacionais. Lisboa: Temas e Debates, 2000.

VAZ, L. Remo no Maranhão, 1900 - 1929. In: DA COSTA, L. (Org.). Atlas do esporte no Brasil: atlas do esporte, educação física e atividades físicas de saúde e lazer no Brasil. Rio de Janeiro: Shape, 2005.

Endereço para correspondência:

Escola de Educação Física - UFRGS

Rua Felizardo, 750 - Jardim Botânico

90690-200 - Porto Alegre - RS

Recebido em: 12.03.2013

Aprovado em: 12.06.2013

Movimento, Porto Alegre, v. 20, n. 01, p. 59-79, jan/mar de 2014. 